\title{
Evaluation Transient Stability of Large Scale Power System with Multi-Terminal HVDC
}

\author{
Prechanon Kumkratug
}

\begin{abstract}
This paper presents the method of evaluating transient stability of large scale power system equipped with multi-terminal high voltage direct current (MTDC). The power system including synchronous machine, transmission network, and HVDC is based on the concepts of stability mode. In addition, various techniques to reduce the simulation time are systematically applied. The proposed method helps us to access the transient stability of the system with MTDC in the much simpler way. The verification of the methods is tested on 20 generators in an IEEE 118-bus system under various cases.
\end{abstract}

Index Terms-Power system, transient stability, HVDC, MTDC.

\section{INTRODUCTION}

Power system stability is to study the behaviors of the synchronous machines after disturbances. Transient stability refers to the ability of all machines in the system to remain in a state of operating equilibrium under normal operating conditions or to regain and acceptable point near equilibrium point after severe and sudden disturbance .High voltage direct current (HVDC) system consisting of two converters has the ability to rapidly control the transmitted active power flow [1]-[2]. The fast acting of power flow control is able to improve transient stability of power system [3]. By adding one or more converter, the MTDC system has a better performance of application in power systems [3]-[7].

For purposes of analyzing transient stability, it is helpful to conceptually ensure that the system must be able to continually supply electrical energy to load with the standard of frequency and voltage. For many years, the novel method to access and improve transient have been proposed by the power system researchers. Momentary and stability modes are widely accepted to verify the power system analysis. When working in momentary mode power system including MTDC system is modeled in detail. For large scale power system analysis, it is very time consuming [9]-[12]. For stability mode power system and MTDC system are modeled in the much simpler way.

This paper presents the method of analyzing transient stability of large scale power equipped with MTDC in stability mode. This paper has the following outline. Section II provides some a mathematical model of the power system and MTDC system. Section III presents the proposed method. In Section IV, the verification of the proposed

Published on July 20, 2020.

Prechanon Kumkratug, Kasetsart University at Sriracha Campus, Thailand.

(corresponding e-mail: prechanon@eng.src.ku.ac.th) control strategy and simulation method is tested on the IEEE 118-bus system with various fault occurrences and MTDC locations. Finally, conclusions are drawn in Section V.

\section{BACKGROUND}

First, consider the power system without MTDC. A single line diagram of a multi-machine system consisting of $n g$ generators is shown in Fig. 1(a). Fig. 1(b) shows the equivalent circuit of Fig. 1(a). Fig. 1(c) is used for evaluating the electrical power output $\left(P_{\mathrm{e}}\right)$ equation of Fig. 1(b). Here $I_{G}$ is the current injection of a synchronous generator. $\quad \mathbf{Y}_{R}$ is the reduced admittance matrix of all physical load buses from bus $n g+l$ to bus $n$. The swing equation of a multi-machine system in the center of inertia (COI) is given by [13]-[14]

$$
\begin{aligned}
& \dot{\tilde{\delta}}_{i}=\tilde{\omega}_{i} \\
& \dot{\tilde{\omega}}_{i}=\frac{1}{M_{i}}\left[P_{i}-P_{e i}-\frac{M_{i}}{M_{T}} P_{C O I}-D_{i} \tilde{\omega}_{i}\right] \quad i=1,2 \ldots n g
\end{aligned}
$$

where

$$
\begin{aligned}
& P_{i}=P_{m i}-E_{i}^{\prime 2} G_{i i} \\
& P_{e i}=\sum_{j=1 ; \neq i}^{n g}\left(C_{i j} \sin \theta_{i j}+D_{i j} \cos \theta_{i j}\right) \\
& P_{C O I}=\sum_{i=1}^{n g}\left(P_{m i}-C_{i j}\right)-2 \sum_{i=1}^{n g} \sum_{j=i+1}^{n g} D_{i j} \cos \theta_{i j} \\
& M_{T}=\sum_{i=1}^{n g} M_{i} \\
& C_{i j}=E_{i}^{\prime} E_{j}^{\prime} B_{i j} \\
& D_{i j}=E_{i}^{\prime} E_{j}^{\prime} G_{i j}
\end{aligned}
$$

and

$$
\theta_{i j}=\theta_{i}-\theta_{j}=\dot{\tilde{\theta}}_{i}-\dot{\tilde{\theta}}_{j}
$$

$G$ and $B$ are the real and imaginary parts in each element of $\mathbf{Y}_{R}$. 
Consider Fig. 2, MTDC system such as 3-terminal HVDC is applied to exchange active power flow $\left(\mathrm{P}_{\mathrm{C}}\right)$ between converters. The active power balance at bus $C_{1}, C_{2}$, and $C_{3}$ is given by

$$
\begin{aligned}
& P_{C 1}^{i n j}=P_{C 1}+P_{L C 1} \\
& P_{C 2}^{i n j}=P_{C 2}+P_{L C 2} \\
& P_{C 3}^{i n j}=P_{C 3}+P_{L C 3}
\end{aligned}
$$

Here $P_{L C}$ is the active power load.

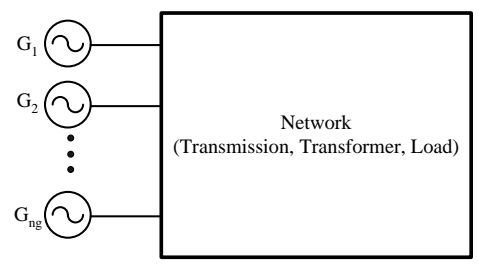

(a)

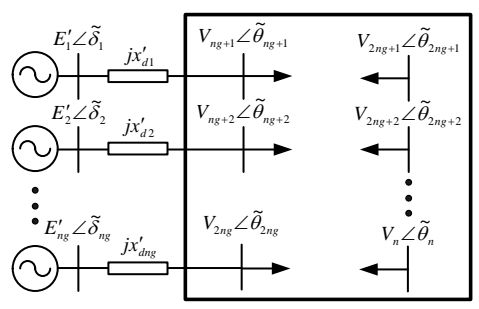

(b)

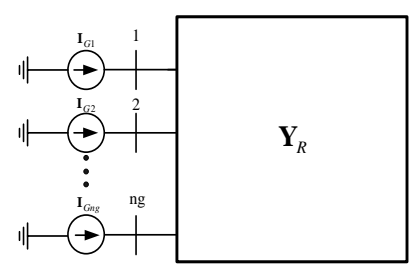

(c)

Fig. 1. A multi-machine power system: (a) single line diagram; (b) simple equivalent circuit; (c) current injection model and reduced admittance matrix representations of the system.

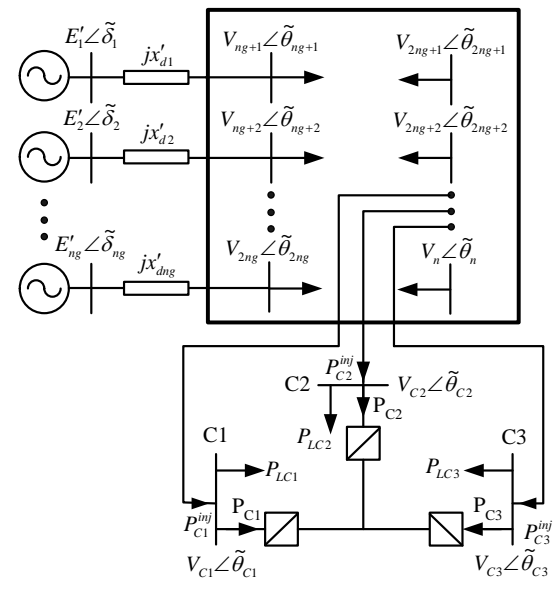

Fig. 2. A multi-machine power system equipped with a 3-terminal HVDC.

\section{A PROPOSED METHOD}

The aim of this section is to develop the simulation method for working with a large scale power system equipped with the MTDC. The proposed simulation method in the form of a flow chart is shown in Fig. 3.

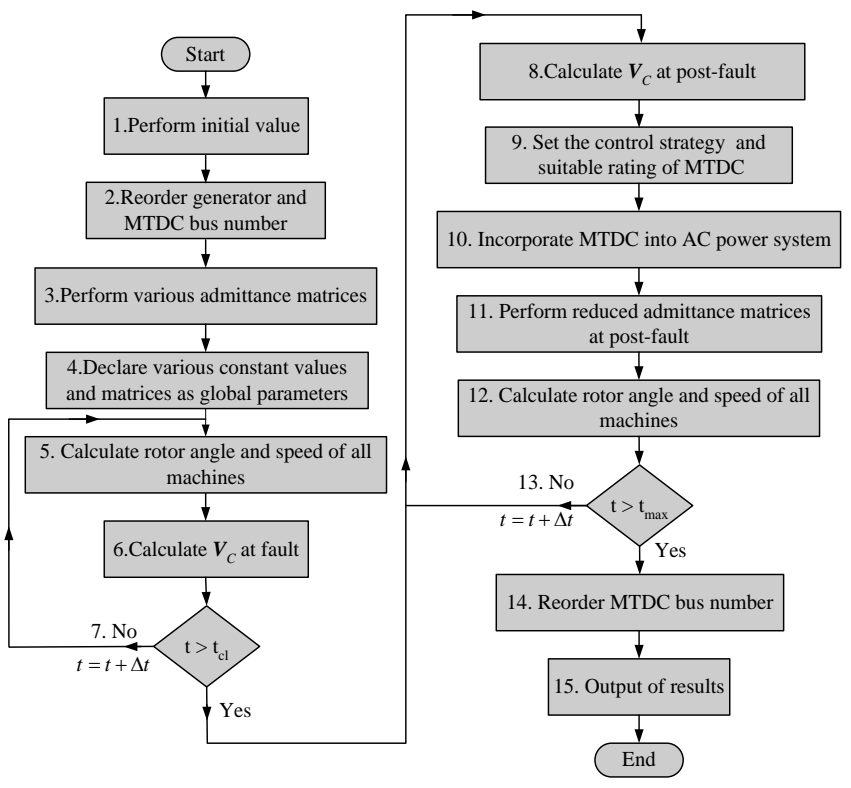

Fig. 3. Flow chart of the proposed method.

A step-by-step description follows:

\section{Pre-fault}

Step 1: Perform the initial operation of the power system at pre-fault such as $P_{m i}, E_{i}^{\prime}$, and $\tilde{\delta}_{i}$.

Step 2: Reorder the constant transient voltage bus and MTDC bus number. To simplify the partitioned admittance matrix formulation, they are numbered consecutively. The constant transient voltage buses are numbered from bus 1 to bus $n g$ whereas the MTDC buses are numbered from bus $n g+1$ to $n g+n c$. Here $n c$ is the number of HVDC terminals.

Step 3: Perform $\mathbf{Y}_{P}^{d}, \mathbf{Y}_{R}^{d}$, and $\mathbf{Y}_{P}^{a}$. The superscripts ' $d$ ' and ' $a$ ' are represented by the admittance matrix at fault and post-fault, respectively. Similarly, the subscripts ' $P$ ' and ' $R$ ' are the admittance matrix by which the physical load buses are partially and entirely reduced, respectively. $\mathbf{Y}_{R}$ is in the order of $(n g \times n g)$ and $\mathbf{Y}_{P}$ is in the order of $(n g+n c \times n g+n c) . \quad \mathbf{Y}_{P}$ is formulated by using the node equation given by

$$
\left[\begin{array}{c}
\mathbf{I}_{G} \\
\mathbf{0}
\end{array}\right]=\left[\begin{array}{cc}
\mathbf{Y}_{P 1}^{d, a} & \mathbf{Y}_{P 2}^{d, a} \\
\mathbf{Y}_{P 3}^{d, a} & \mathbf{Y}_{P 4}^{d, a}
\end{array}\right]\left[\begin{array}{c}
\mathbf{E}^{\prime} \\
\mathbf{V}_{C}
\end{array}\right]
$$

Here,

$\mathbf{Y}_{P 1}^{d, a}$ is the order of $(n g \times n g)$;

$\mathbf{Y}_{P 2}^{d, a}$ is the order of $(n g \times n c)$;

$\mathbf{Y}_{P 3}^{d, a}$ is the order of $(n c \times n g)$;

$\mathbf{Y}_{P 4}^{d, a}$ is the order of $(n c \times n c)$;

$\mathbf{V}_{C}$ is the ac vector voltage of MTDC buses. 
Step 4: Declare $P_{m}, E_{i}^{\prime}, \tilde{\delta}_{i}, \mathbf{Y}_{P}^{d}, \mathbf{Y}_{R}^{d}$, and $\mathbf{Y}_{P}^{a}$ as global variables.

\section{Fault}

Step 5: Use $\mathbf{Y}_{R}^{d}$ to calculate the current injection of generator $\left(\mathbf{I}_{G}\right)$, the output of electrical power, and to evaluate the rotor angles and machine speeds from (1) and (2), respectively.

Step 6: Calculate $V_{\mathrm{C}}$ as given by

$$
\left.\left[\mathbf{V}_{C}\right]=-\left[\mathbf{Y}_{P 4}^{d}\right]^{-1}\left[\mathbf{Y}_{P 3}^{d}\right] \mathbf{E}^{\prime}\right]
$$

Step 7: Increase the step time $(\Delta t)$ and repeat step (5) to (6) until the clearing fault time $\left(t_{c l}\right)$ is reached.

\section{Post-fault}

Step 8: Calculate $\boldsymbol{V}_{C}$ at post-fault by replacing $\mathbf{Y}_{P 3}^{d}$ and $\mathbf{Y}_{P 4}^{d}$ in (21) with $\mathbf{Y}_{P 3}^{a}$ and $\mathbf{Y}_{P 4}^{a}$, respectively.

Step 9: Determine the suitable active power injection $\left(P_{C}\right)$ depending on the control strategy.

Step 10: Incorporate the MDCT system into the ac networks. $P_{C}$ is converted to the current injection $\left(I_{C}\right)$ as shown in Fig. 4 (a). Adding $\left(I_{C} / V_{C}\right)$ to the diagonal elements of $\mathbf{Y}_{P 4}^{a}$, the new $\mathbf{Y}_{P 4}^{a}$ is defined by $\mathbf{Y}_{P 4, H}^{a}$ in the node equation of

$$
\left[\begin{array}{l}
\mathbf{I}_{G} \\
\mathbf{0}
\end{array}\right]=\left[\begin{array}{l|l}
\mathbf{Y}_{P 1}^{a} & \mathbf{Y}_{P 2}^{a} \\
\mathbf{Y}_{P 3}^{a} & \mathbf{Y}_{P 4, H}^{a}
\end{array}\right]\left[\begin{array}{l}
\mathbf{E}^{\prime} \\
\mathbf{V}_{C}
\end{array}\right]
$$

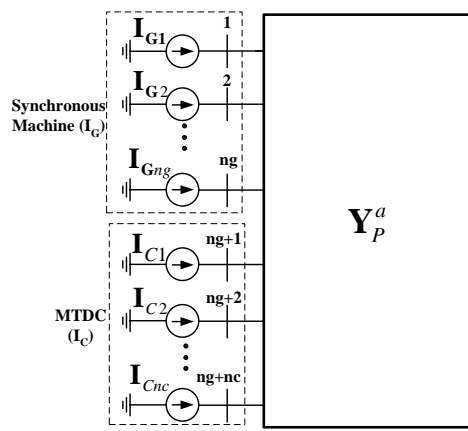

(a)

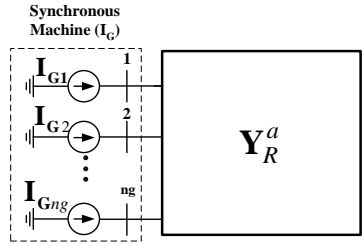

(b)
Fig. 4. Successive method of incorporation of MTDC to power system: (a) current injection models of machine and MTDC (b) reduced admittance matrix of power system with MTDC.

Step 11: Perform $Y_{R}^{a}$ as shown in Fig. 4(b) by eliminating MTDC bus.

Step 12: Use $\mathbf{Y}_{R}^{a}$ to calculate the current injection of generator $\left(\mathbf{I}_{G}\right)$, the output of electrical power, the rotor angles (1), and machine speeds (2), respectively.

Step 13: Increase the step time $(\Delta t)$ and repeat step (7) to step (12) until the maximum time $\left(t_{\max }\right)$ is obtained.

Step 14: Reorder the MTDC buses as they appear in a single line diagram.
Step 15: Display the simulation results.

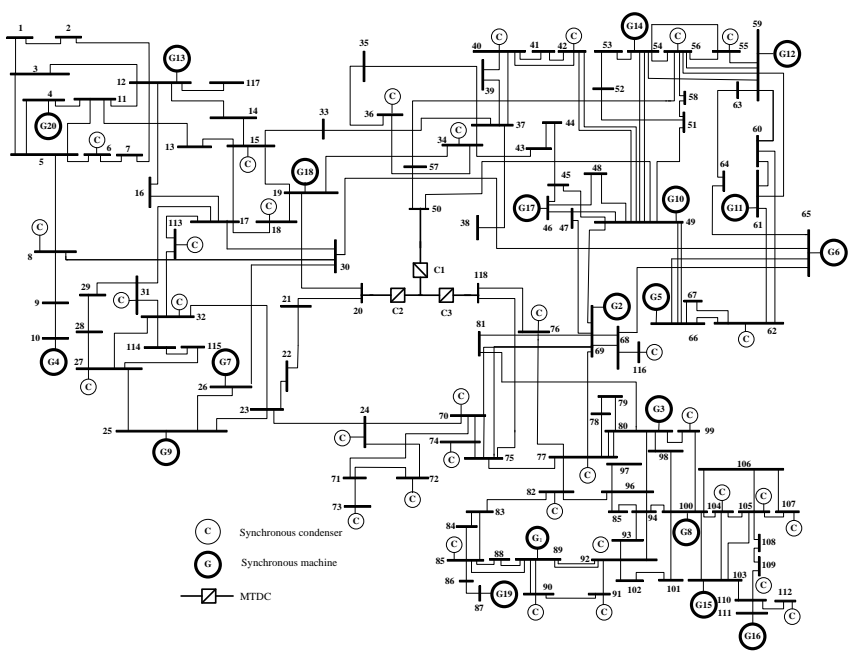

Fig. 5. Single line diagram of the IEEE 118-bus system equipped with the MTDC.

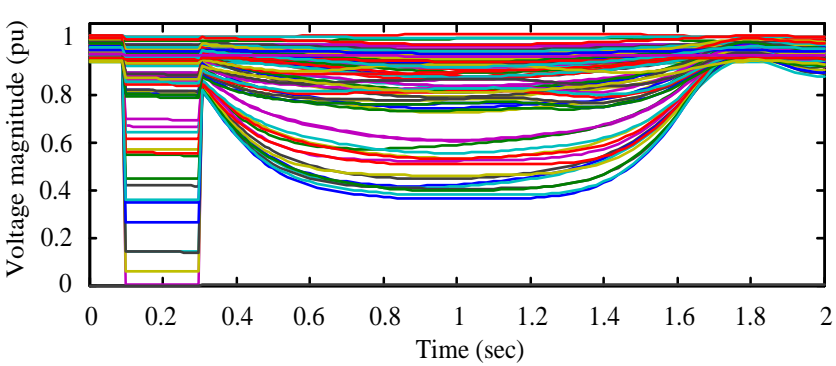

(a)

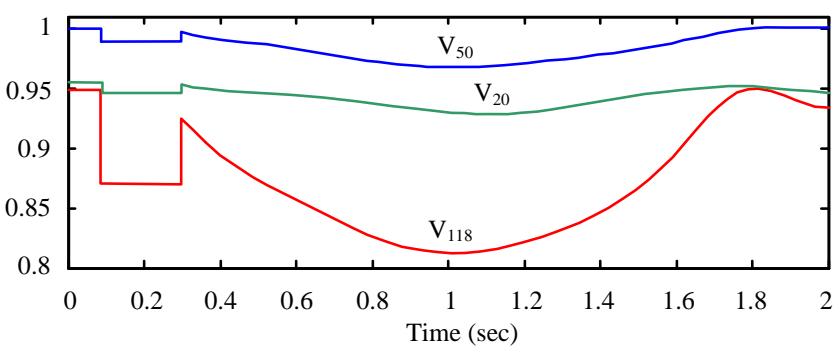

(b)

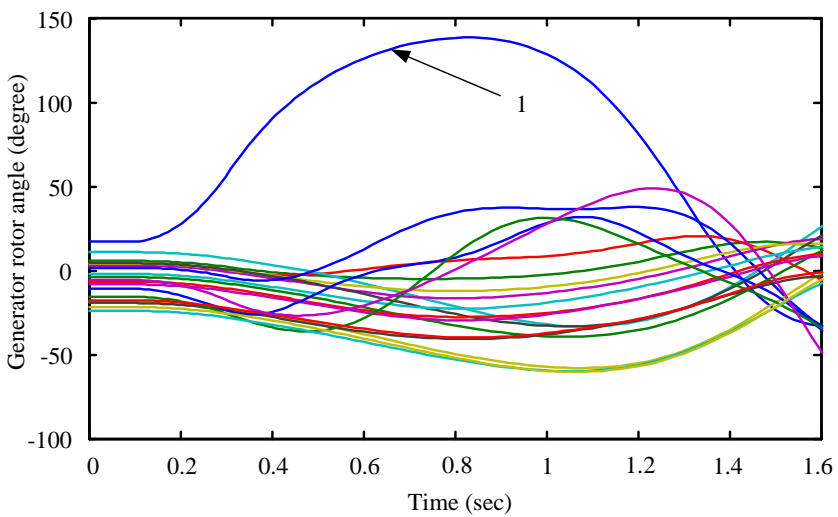

(c)

Fig. 6. Results of the system without MTDC for first case of fault occurrence: (a) voltage at 118 bus (b) voltage at MTDC bus (c) generator rotor angle. 


\section{Simulation Results}

Fig. 5 shows the IEEE 118-bus system used to verify the proposed method. It consists of 32 synchronous condensers, 20 synchronous generators, and 186 transmission lines. The system data for the power flow analysis was reported in [15]. The data of the 20 synchronous generators for the transient stability analysis was reported in [16]. The MTDC is arbitrary in the center of the system: Firstly, it is considered that a temporary three phase fault occurs at bus 84. Fig. 6 shows the results of the system without MTDC for clearing time $\left(t_{c l}\right)=112 \mathrm{msec}$. The system is considered as unstable. Fig. 7 shows the system with $t_{c l}=113 \mathrm{msec}$. The system is considered unstable. In this case of fault occurrence, the critical clearing time is 112-113 msec. However, with MTDC, the system can increase the robustness of the system as shown in Fig. 8(a). The active power flow control is shown in Fig. 8(b). The second case study is to assume that three phase fault appears at bus 15 . The swing curve is shown in Fig. 9. It can be observed in the Fig. 9(a) and Fig. 9(b) the MTDC can enhance transient stability of large scale power system.

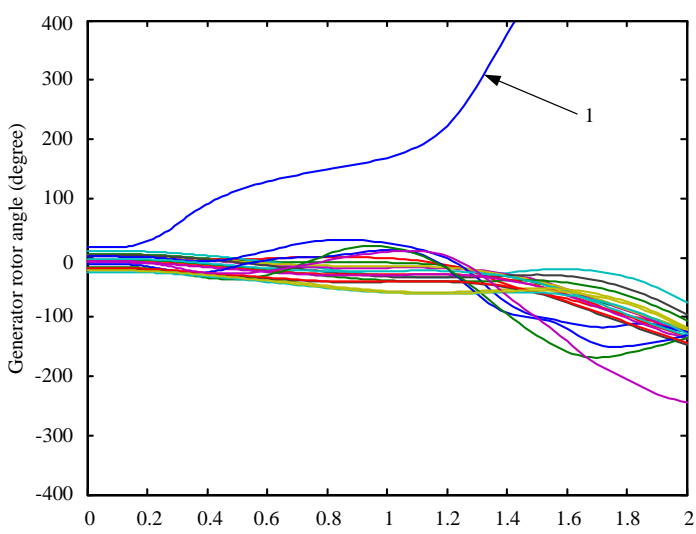

Fig. 7. Generator rotor angle of the system for second case.

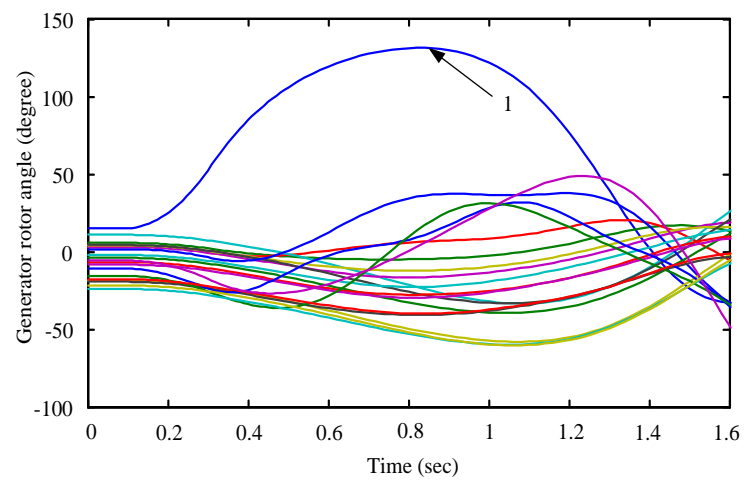

(a)

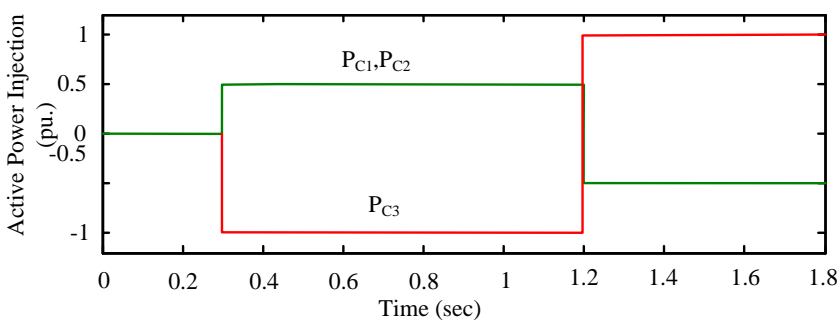

(b)

Fig. 8. The system with MTDC for the third case: (a) generator rotor angle (b) active power injection of MTDC.

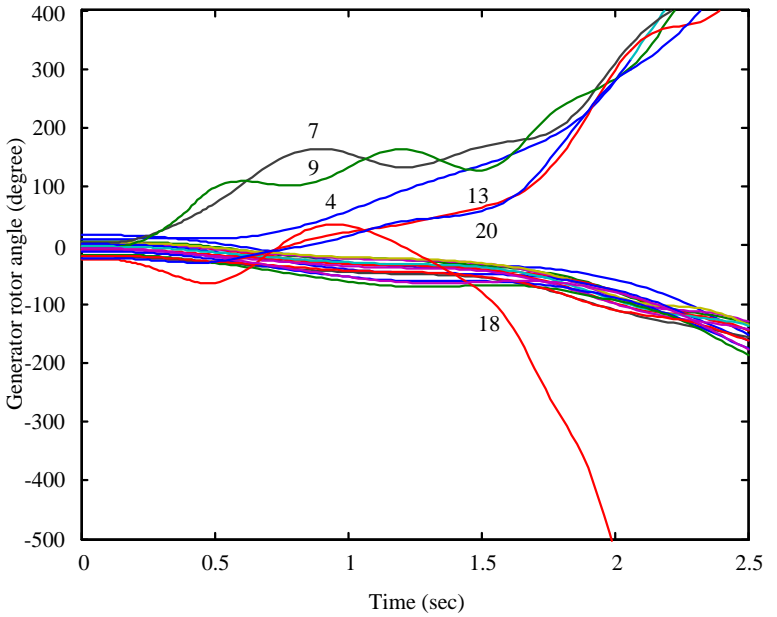

(a)

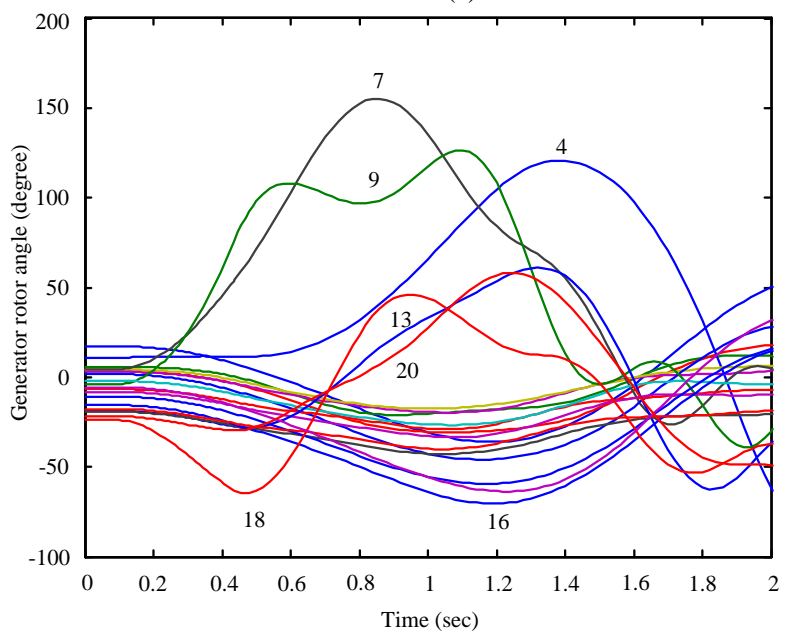

(b)

Fig. 9. Results of the system for second case of fault occurrence: (a) without MTDC (b) with MTDC.

\section{CONCLUSION}

The proposed simulation method for evaluating the transient stability of a large scale power system equipped with MTDC is proposed in this paper. All the constant values and matrices are performed and declared as global variables at steady state analysis. During the transient stability analysis, the control of the MTDC will only change the diagonal of the partially reduced admittance matrix of the system.

The main reasons behind the fast simulation in this proposed method are:

1) Working with much smaller matrix dimensions. It is time consuming by using the structure preserving network model as shown in Fig. 2. The matrix dimension in this model is the order of $(n \times n)$. The proposed method deals with the structure reduced network model as shown in Fig. 4. The maximum matrix dimension is reduced to the order of $(n g+n c \times n g+n c)$.

2) Performing the partially reduced admittance matrix and declaring it as a global variable before evaluating the transient stability of the system. Its diagonal of $\mathbf{Y}_{P 4}^{a}$ which is a small matrix dimension $(n c+n c)$ can potentially be modified when the MTDC is controlled at the post fault. 


\section{REFERENCES}

[1] R. Eriksson, "On the centralized nonlinear control of HVDC systems using Lyapunov theory," IEEE Trans. Power Del., vol. 28, no. 2, pp. 1156-1163, Apr. 2014.

[2] W. Feng, L. A. Tuan, L. B. Tjernberg, A. Mannikoff, and A. Bergman, "A new approach for benefit evaluation of multiterminal VSC-HVDC using a proposed mixed ac/dc optimal power flow," IEEE Trans. Power Syst., vol. 29, no. 1, pp. 432-443, Feb. 2014.

[3] J. Stefan G, A. Gunnar, J. Erik, and R. Roberto, "Power system stability benefits with VSC DC-transmission systems," in Proc. CIGRE Conf., Paris, France, 2004.

[4] L. Wang and L. Y. Chen, "Reduction of power fluctuations of a large scale grid-connected offshore wind farm using a variable frequency transformer," IEEE Trans. Sustainable Energy, vol. 2, no. 3, pp. 226234, Jul. 2011.

[5] N. R. Chaudhuri, R. Majumder, and B. Chaudhuri, "System frequency support through multi-terminal DC (MTDC) grids," IEEE Trans. Power Syst., vol. 28, no. 1, pp. 347-356, Feb. 2013.

[6] L. Harnefors, N. Johansson, L. Zhang, and B. Berggren, "Interarea Oscillation Damping Using Active-Power Modulation of Multiterminal HVDC Transmission," IEEE Trans. Power Syst., 2014 to be published.

[7] R. Eriksson, "Coordinated control of multiterminal DC grid power injections for improved rotor-angle stability based on Lyapunov theory," IEEE Trans. Power Del., 2014, to be published.

[8] N. R. Chaudhuri, and B. Chaudhuri, "Adaptive droop control for effective power sharing in multi-terminal DC (MTDC) grids," IEEE Trans. Power Syst., vol. 28, no. 1, pp. 347-356, Feb. 2013.

[9] J. Peralta, H. Saad, S. Dennetière, J. Mahseredjian, and S. Nguefeu, "Detailed and averaged models for a 401-level MMC-HVDC system,"

IEEE Trans. Power Del., vol. 27, no. 3, pp. 1501-1508, Jul. 2012.

[10] Q. Ding, T. S. Chung, and B. Zhang, "An improved sequential method for AC/MTDC power system state estimation," IEEE Trans. Power Syst., vol. 16, no. 3, pp. 506-512, Feb. 2001.

[11] J. Beerten, S. Cole, and R. Belmans, "Modeling of multi-terminal VSC HVDC systems with distributed DC voltage control," IEEE Trans. Power Syst., vol. 29, no. 1, pp. 34-42, Jan. 2014.

[12] S. Liu, Z. Xu, W. Hua, G. Tang, and Y. Xue, "Electromechanical transient modeling of modular multilevel converter based multiterminal HVDC systems," IEEE Trans. Power Syst., vol. 29, no. 1, pp. 72-83, Jan. 2014.

[13] M. A. Pai, Energy function analysis for power system stability, Massachusetts: Kluwer Academic Publishers, 1981.

[14] V. Azbe, U. Gabrijel, D. Povh and R. Mihalic, "The energy function of a general multimachine system with a unified power flow controller," IEEE Trans. Power Syst., vol. 20, no.3, pp. 1478-1485, Aug. 2005.

[15] [Online]. Available: https://www.ee.washington.edu/research/pstca /pf118/pg_tca118bus.htm.

[16] A. Athay, R. Podmore, and S. Virmani, "A practical method for the direct analysis of transient stability," IEEE Trans. Power Syst., vol. PAS-98, no. 2, pp. 573-584, Mar-Apr. 1979.

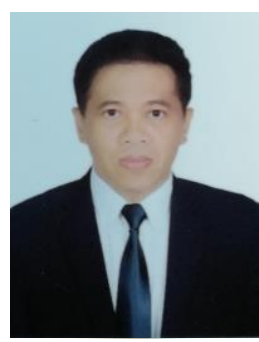

Prechanon Kumkratug received his B.E., M.E., and D.E. degrees from King Mongkut's Institute of Technology Ladkrabang, in 1996, Asian Institute of Technology, in 1999, and Kasetsart University at Bang Khean Campus, in 2008, respectively. His employment experience included the Advanced Info Services plc, Mahanakorn University, King Monkut's Institute of Technology Thonburi, and Eastern Asian University. $\mathrm{He}$ is currently employed as an Associate Professor at the Department of Electrical and Electronics Engineering, Kasetsart University, Sri Racha Campus. 